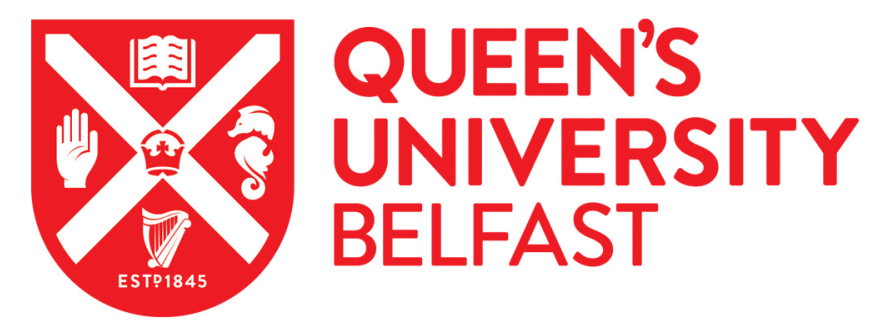

\title{
The 'Good Friday Agreement' and cancer research on the island of Ireland: Evidence for the impact of a tripartite cancer research
} partnership

Lewison, G., Gavin, A., McCallion, K., McDermott, R., Sullivan, R., \& Lawler, M. (2020). The 'Good Friday Agreement' and cancer research on the island of Ireland: Evidence for the impact of a tripartite cancer research partnership. European journal of cancer (Oxford, England : 1990), 129, 15-22.

https://doi.org/10.1016/j.ejca.2020.01.014

Published in:

European journal of cancer (Oxford, England : 1990)

Document Version:

Peer reviewed version

Queen's University Belfast - Research Portal:

Link to publication record in Queen's University Belfast Research Portal

\begin{abstract}
Publisher rights
Copyright 2020 Elsevier Ltd.

This manuscript is distributed under a Creative Commons Attribution-NonCommercial-NoDerivs License

(https://creativecommons.org/licenses/by-nc-nd/4.0/), which permits distribution and reproduction for non-commercial purposes, provided the author and source are cited.

\section{General rights}

Copyright for the publications made accessible via the Queen's University Belfast Research Portal is retained by the author(s) and / or other copyright owners and it is a condition of accessing these publications that users recognise and abide by the legal requirements associated with these rights.
\end{abstract}

\section{Take down policy}

The Research Portal is Queen's institutional repository that provides access to Queen's research output. Every effort has been made to ensure that content in the Research Portal does not infringe any person's rights, or applicable UK laws. If you discover content in the Research Portal that you believe breaches copyright or violates any law, please contact openaccess@qub.ac.uk. 


\section{The "Good Friday Agreement" and cancer research on the island of Ireland: Evidence for the impact of a tripartite cancer research partnership}

Grant Lewison,' Anna Gavin, ${ }^{2}$ Karen McCallion, ${ }^{3}$ Ray McDermott, ${ }^{4}$ Richard Sullivan' and Mark Lawler ${ }^{5}$

'King's College London, Institute of Cancer Policy, Department of Cancer and Pharmaceutical Studies, Guy's Hospital, Great Maze Pond, London SEI 9RT, UK; grantlewison@aol.co.uk; richard.sullivan@kcl.ac.uk;

${ }^{2}$ Northern Ireland Cancer Registry, Centre for Public Health, Queen's University Belfast, Belfast UK; a.gavin@qub.ac.uk;

${ }^{3}$ InterTradelreland, Old Gasworks Business Park, Kilmorey St, Newry BT34 2DE, UK; karen.mccallion@intertradeireland.com

${ }^{4}$ Cancer Trials Ireland, Old Finglas Road Glasnevin, Dublin, Ireland; raymcdermott@tuh.ie

${ }^{5}$ Centre for Cancer Research and Cell Biology, Queen's University Belfast, Belfast BT9 7AE, UK mark.lawler@qub.ac.uk (Corresponding Author);

\section{Abstract}

Aim: In 1999, a cooperative tripartite cancer research and training agreement was signed between Ireland (IE), Northern Ireland (NI) and the United States (US) National Cancer Institute $(\mathrm{NCl})$, giving rise to the All-Ireland Cancer Consortium (AICC). We wished to consider if AICC increased the amount/impact of cancer research on the island of Ireland and what effect this enhanced research activity had on cancer services and cancer outcomes.

Methods: As comparator, we chose the city regions of Copenhagen (CPH), and Lund \& Malmö (L\&M), whose physical connection was greatly improved following construction of bridges between Denmark and Sweden around the time AICC was established. We analysed cancer research outputs from all four geographical regions in the Web of Science (1988-2017), with a particular focus on citations and journal impact factors. We evaluated DisabilityAdjusted-Life-Years (DALYs) as an indicator of change in health status.

Results: Research outputs increased in all four regions, but more in IE/NI than in the Scandinavian cities, while collaboration between IE and NI, and both the USA and the Rest of 
Europe, increased even more substantially. Citation scores also showed a greater improvement for IE and NI. Journal citation impact factors indicated that IE/NI papers were increasingly being published in more highly-cited journals. Research-enabled cancer service provision improved on the island of Ireland, with concomitant increases in cancer survival.

Conclusion: The AICC collaborative agreement delivered significant additionality on the island of Ireland, promoting transnational cooperation, enhancing cancer research activity and underpinning improved cancer services and better cancer outcomes.

\section{Introduction}

In October 1999, a Memorandum of Understanding (MOU) was signed between representatives of the governments of Ireland (IE) and Northern Ireland (NI), and the US

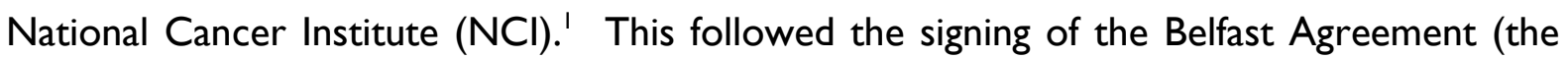
"Good Friday" Agreement), on 10 April 1998² and its approval in referenda in both IE and NI on 22 May 1998. The MOU formed the basis for the All-Ireland Cancer Consortium (AICC), a tripartite partnership that aimed "to reduce cancer incidence and mortality on the island of Ireland through cross-border and transatlantic collaborations in cancer research and education". ${ }^{3}$ AICC was the brainchild of Professor Patrick Johnston, a UK leader in cancer research, who had worked at $\mathrm{NCl}$ and recognised the significant opportunity that such a tripartite partnership could bring to enhance cancer research and control on the island of Ireland. At the same time, the Great Belt ${ }^{4}$ and $Ø$ resund ${ }^{5}$ bridges were constructed (in 199798 and 2000, respectively), between mainland Denmark and Copenhagen and between Copenhagen and Malmö, so that Denmark and Sweden were for the first time connected with road and rail links. This might have been expected to facilitate increased collaboration in research (including cancer research) between Copenhagen (CPH) and Malmö \& Lund (M\&L) (Lund University has an additional campus in Malmö).

Given AICC's focus on cancer research and its potential impact, we aimed to investigate how AICC-driven initiatives/activities in the last two decades may have influenced collaborative research between the two jurisdictions and enhanced cancer research outputs on the island of Ireland. Additionally, we attempted to identify any health benefits that accrued from AICC's activities, reflected in research-informed improved cancer services and their effect on cancer burden. We estimated this burden as Disability-Adjusted-Life-Years (DALYs) per thousand inhabitants. DALYs takes account both of early death and the pain/disability experienced by 
patients. Given the major changes in cancer incidence/mortality in Europe during the last 30 years, we sought comparisons with Denmark and Sweden, in order to determine if changes occurring in IE/NI were more beneficial than those in Scandinavia over the same time period. We hypothesised that collaboration between IE and $\mathrm{NI}$, and between either jurisdiction and USA, would increase more rapidly than with the rest of Europe, and that collaboration between the two Scandinavian cities would also increase faster than for either with other European countries. We postulated that research paper output would show the benefits of both AICC and the Scandinavian cities physical linkage, with higher $\mathrm{ACl}$ values and, for IE/NI, higher journal citation impact factors.

\section{Methodology}

We identified cancer research publications from 1988 (over a decade before AICC's inauguration) to 2017 , from both IE and NI. Since bibliometric data always need normalisation, we analysed outputs from another pair of European geographical entities ( $\mathrm{CPH}, \mathrm{M \& L})$, where two events, in close proximity (the opening of the bridges), took place at approximately the same time as AICC's formation.

A complex filter ${ }^{7}$ for cancer research was applied to the Web of Science (WoS, (C) Clarivate Analytics) for the 30 year period (1988-20I7). Articles and reviews published by IE/NI researchers were retrieved $(n=9218)$. Full paper details were downloaded as text files and converted to Excel spreadsheets for analysis. We marked each "island of Ireland" paper with its integer count for IE and $\mathrm{NI}$ ( I or 0), and with its fractional counts for these two regions, for the UK, for USA, and for the remaining 26 Member States of the EU, plus Iceland, Norway and Switzerland (EUR29)). Separately, numbers of cancer papers in the same years from CPH, or from L\&M, or both, were determined with the WoS software for each of the 30 years in the measurement period.

For both sets of papers, numbers of WoS citations in a five-year window, beginning with the year of publication, were determined for papers in each year(1988-2013), and grouped into five five-year cohorts, except for the first cohort, which was six years. Another measure of quality of IE/NI papers is the impact factor of the journals in which they were published. We determined this for each journal, using "diachronous" citations (average numbers of citations received in years $\mathrm{t}, \mathrm{t}+\mathrm{I}, \mathrm{t}+2, \mathrm{t}+3$ and $\mathrm{t}+4$ for papers published in year $\mathrm{t}$ ). These scores were designated Actual Citation Impact ( $\mathrm{ACl}$ ) and Potential Citation Impact (PCI), respectively. 
Disease burden data (in DALYs) are published by the World Health Organization (WHO), and the Institute for Health Metrics and Evaluation (IHME). ${ }^{8}$ Both give DALYs for 29 cancer anatomical sites, but only IHME provides separate data for NI. We determined the number of DALYs per thousand of the relevant populations for every five year period(1990-2017) from both sources, although WHO data were not available until the year 2000.

\section{Results}

Figure I shows cancer research paper outputs from IE only, from $\mathrm{NI}$ only, and from both regions over the 30-year period, presented as five-year running averages so as to reduce yearto-year variation. IE output has almost doubled from $0.25 \%$ of the world total in the $1990 \mathrm{~s}$ to $0.48 \%$ in the last decade; that of $\mathrm{NI}$ has increased from $0.13 \%$ to $0.19 \%$ in the same period. Joint publications increased from $0.0023 \%$ of the world total in the $1990 \mathrm{~s}$, to $0.01 \%$ in the 2000s and $0.019 \%$ in the $2010 \mathrm{~s}$, a greater than eight-fold increase between first and last decades. Actual numbers of papers rose even faster, from 8 in the 1990s, to 54 in the 2000s and 136 in the eight years of the last decade (equivalent to 170 papers in the full decade), or by $>20$-fold. If in 20I4- I6, IE had selected its foreign partners (which contributed 574.2 papers out of IE's total of I386) proportionately to their presence in world cancer research, then in those years it would have had a contribution from $\mathrm{NI}$ of only $0.18 \%$, or 1.03 papers, instead of the actual contribution of 13.6 papers. For all data presented above, differences between expected and observed number of publications are very highly significant ( $p<0.01 \%$ ).

In comparison, corresponding results for CPH and L\&M have a rather different pattern (Figure 2). Output from the two Swedish cities declined slightly, relative to the rest of the world (although it expanded in absolute terms from I 24 in 1988-89 to 472 in 2015-16), while output from CPH declined relatively in the period from 1994-200I, but has since increased. The opening of the two bridges was associated with an increase in the numbers of papers from both city regions, from 62 in the 1990s to 263 in the 2000s and 563 in 2010-17, equivalent to 704 in the full decade. The ratio between last and first decades was $704 / 62$ or 11.35 , only $53 \%$ of the increase on the island of Ireland. On the same basis as for IE/NI, CPH in 20I4-16 published $230 \mathrm{I}$ papers, with its fractional contribution 967.3 papers, so its "foreign" contribution was 1333.7 papers, of which L\&M contributed 28.8 papers. These two cities only published $0.17 \%$ of the world total (on a fractional count basis), but represented $28.8 / 1333.7=2.16 \%$ of CPH's "foreign" contribution, so they were preferentially favoured by a factor of $2.16 / 0.17=12.7$. 
In terms of citations, $\mathrm{ACl}$ values increased rapidly for IE/NI papers (Figure 3). For the totality of papers, the mean rose from 7.4 in 1988-93 to 23.3 in 2009-13. By way of comparison, the mean score for EUR3 I cancer papers in 2002-09 was 17 citations, increasing very slowly, so IE/NI papers were better cited than the European average. Within these, IE-alone papers were the best cited up to 2003 , NI-alone papers were marginally the better cited after 2008 , but since 2003, combined publications from IE/NI have received more citations than those from either region individually, reflecting the potential cross-jurisdictional impact of AICC.

Figure 4 shows the diachronous five-year citation counts (potential citation impact, $\mathrm{PCl}$ ) for $\mathrm{IE} / \mathrm{NI}$ cancer papers. Results are comparable with $\mathrm{ACl}$ values, showing that IE/NI papers are cited about as frequently as the average papers in their chosen journals. Papers from both IE and $\mathrm{NI}$ have been published in progressively more highly-cited journals, as their numbers have increased. $\mathrm{NI}$-only papers are now being published in journals with slightly higher impact than IE-only papers, whereas in 1994-98 the reverse was the case.

In order to investigate whether IE/NI cancer researchers' choice of journals and publication success in those journals was improving, we tabulated $\mathrm{PCl}$ values of all journals $(n=|| 28)$ in which they published over the period 1988-2004, in every even year (1988, 1990, etc.). We averaged $\mathrm{PCl}$ values for the whole "basket" of journals (i.e. the average $\mathrm{PCl}$ value for the journals in which island of Ireland researchers published in each year) and compared this with mean $\mathrm{PCl}$ for IE/NI papers (Figure 5). Whereas in the period up to 1994 , IE/NI researchers were less ambitious in their journal selection, after that year their journal selection (and indeed success) were of higher citation impact, particularly post-2005 (Figure 5).

Corresponding citation performances of CPH and L\&M are shown in Figure 6. The scale is different; these papers are better cited than IE/NI papers, with the same tendency for later papers to be better cited, and for ones involving both city regions to be uniformly the best cited of the three groups.

We next examined the percentage of papers in each group that were co-authored with either USA or other European countries in six five-year periods (Figures 7, 8). IE/NI researchers have dramatically increased their collaboration with USA, so that now almost a quarter of IE/NI cancer research papers have an American co-author (Figure 7, highly significant $\mathrm{P}<<0.01$ ), whereas for $\mathrm{CPH}$, collaborative cancer research with US researchers has diminished in percentage terms following the opening of the two bridges, while for L\&M it has remained constant at $\sim 5 \%$ (Figure 8 ). 
Collaboration with Europe has also risen dramatically for IE/NI researchers; their mean presence rose from $7.2 \%$ in $1988-92$ to $29.7 \%$ in $2013-17$, a $312 \%$ increase (Figure 8 , highly significant $\mathrm{p}<<0.0 \mathrm{I})$. The effect of the construction of the two bridges was much less, as both CPH and L\&M researchers were already collaborating extensively with EUR29, and EUR29 presence in their research papers only rose from $12.1 \%$ in $1988-92$ to $18.1 \%$ in $2013-17$, a $50 \%$ increase (Figure 8). L\&M cancer researchers are well linked with other European countries, though collaboration has decreased in the last quinquennium. However, for $\mathrm{CPH}$, European collaboration peaked in the late 1990s (before the opening of the bridges) and has since slightly declined, and is now much less than for L\&M, and for both IE and NI (Figure 8).

Changes in cancer burden in the four regions were less dramatic. Variations in numbers of DALYs per thousand people are shown in Figure 9, for IHME/WHO data. These two sources clearly differ, though they show the same time trends, with gradual and steady reductions in three of the four regions. Cancer DALYs in IE are now $\sim 10 \%$ less than in 1990, while a smaller decrease is observed in NI. Denmark has the greatest cancer burden according to both data sets.

\section{Discussion}

This paper represents the first peer-review published study capturing overall cancer research activity across the island of Ireland (IE and NI). Information on cancer research activity in IE was published recently as part of a pan-European study, ${ }^{6}$ but not on specific outputs from $\mathrm{NI}$, which are investigated in the present study.

Collaboration in cancer research increased on the island of Ireland almost two-fold after AICC commenced; almost twice as much when compared to CPH and L\&M post-bridges construction. AICC-driven initiatives included creation of a functioning all-island cancer clinical trials network (now called Cancer Trials Ireland ${ }^{9}$ ), development of a scholar exchange programme for IE/NI researchers with $\mathrm{NCl}$ and participation of IE/NI researchers in the $\mathrm{NCl}$ cancer prevention fellowship programme. We believe that these activities have helped increase collaborative cancer research activity and enhanced cancer research quality on the island of Ireland. Our analyses suggest that AICC influenced both the amount of cancer research and its impact within the global research community.

Citation scores for the Scandinavian cities rose by a factor of $\sim 2.3$ between 1988-93 and 200913, but they rose even more on the island of Ireland, by a factor of $\sim 3.3$. The increase was 
particularly marked in $\mathrm{NI}$, where $\mathrm{ACl}$ increased from 4 to 25 , or more than six-fold. Specific factors that presumably contributed to this increase include development of a dedicated $\mathrm{NI}$ cancer research facility, with the Centre for Cancer Research and Cell Biology opening on Queen's University Belfast's campus in $2007,{ }^{10}$ the Northern Ireland Biobank ${ }^{10,} 11$ and Northern Ireland Molecular Pathology Laboratory ${ }^{10,12}$ (opened in $201 \mathrm{I}$ and 2013 respectively) which underpinned an uplift in translational cancer research in $\mathrm{NI}$, and the highly-cited work of the research-active Centre for Public Health, led by the late Professor Liam Murray which includes the Northern Ireland Cancer Registry (NICR). ${ }^{13,14}$ Research-enabled improvement in cancer services ${ }^{10}$ contributed to significantly enhanced patient care in $\mathrm{NI}$, recognised by the 2012 Queen Elizabeth Anniversary prize for the NI Comprehensive Cancer Centre.

Increases in citation scores on the island of Ireland were probably assisted by the research being published in higher impact journals and may also reflect the increased presence of USA and continental European researchers on IE/NI-originating publications.

We recognise that associations do not imply causality. Additionally, research initiatives can take several years to mature and produce relevant outputs. Other factors not measured in the current study include cancer research funding spend on the island of Ireland. Nonetheless, AICC appears to have achieved its stated objectives with regard to cancer research outputs. It has also potentially helped influence the documented improved survival experienced across the island of Ireland, ${ }^{15}$ and the cancer burden reduction seen in IE, but less so in NI. This difference may reflect other factors - IE published its first National Cancer Strategy in 1996 ${ }^{16}$ and has updated it twice (in $2006^{17}$ and $2017^{18}$ ), whereas Nl's current Cancer Control Strategy has not been updated since $2008 .^{19}$

Given the UK's exit from the EU, approaches that ensure sustained cooperative cancer research activity between IE and $\mathrm{NI}$ would yield significant benefits for researchers, health systems and most importantly citizens on the island of Ireland and should be proactively pursued. The US Ireland R\&D Partnership Programme ${ }^{20}$ provides multi-jurisdictional cofunding of research (including cancer research) for collaborations involving researchers from NI, IE and USA; it presumably has contributed to the enhanced research activity observed between the three jurisdictions and should be expanded. The recently-announced Science Foundation Ireland-funded Precision Oncology Ireland initiative ${ }^{21}$ in IE may provide the impetus for development of an all-island cancer research institute that specifically addresses challenges that cancer patients and health systems are experiencing in both political 
jurisdictions, while also contributing to the global cancer research effort. Cancer does not respect political borders, so why should we? Such an initiative would also honour the legacy of Professor Johnston, whose vision was crucial in developing AICC, but who sadly passed away suddenly in June 2017. This study also provides a robust framework for evaluating the long-term impact of public policies (especially those involving trans-national cooperation), on enhancing research and improving patient outcomes.

\section{Acknowledgement}

GL and RS were supported on ESRC grant UK Research and Innovation GCRF Research for Health in Conflict (R4HC-MENA); developing capability, partnerships and research in the Middle and Near East (MENA) ES/PO 10962/I. ML is in receipt of funding from MRC, CRUK and HDRUK The authors are grateful to Philip Roe of Evaluametrics Ltd for developing the VBA macros used for the data extraction, processing of the downloaded papers, and their analysis. The determination of $\mathrm{PCl}$ values for the journals was performed by Mohima Chowdury, Jill Larmer, Hamish Sharp, and Issy Urquhart, with funding from Queen's University Belfast.

Conflict of Interest: ML declares honoraria from EMD Serono, Pfizer and Roche unrelated to this work; ML and RS declare and unrestricted educational grant from Pfizer for research unrelatred to this paper. All other authors declare no conflict of interest 


\section{References}

I. http://theoncologist.alphamedpress.org/content/5/5/385.full

2. https://www.gov.uk/government/publications/the-belfast-agreement

3. Johnston PG, Daly PA. The NCl-Ireland consortium: a unique international partnership in cancer care._Oncologist. 200I; 6:453-8.

\section{4. https://en.wikipedia.org/wiki/Great_Belt_Fixed_Link}

5. https://en.wikipedia.org/wiki/\%C3\%98resund_Bridge

6. Begum M, Lewison G, Lawler M and Sullivan R. Mapping the European cancer research landscape: An evidence base for national and Pan-European research and funding. Eur J Canc. 2018; 100: 75-84.

7. Lewison G. Definition of Cancer Research: Journals, Titles, Abstracts or Keywords? DESIDOC J Libr Inf Tech. 20I I; 31 : 333-339.

\section{8. http://ghdx.healthdata.org/gbd-results-tool}

\section{9. https://www.cancertrials.ie/}

10. Lawler M, Gavin A, Salto-Tellez M, Kennedy RD, Van Schaeybroeck S, Wilson RH, Harkin DP, Grayson M, Boyd RE, Hamilton PW, McArt DG, James J, Robson T, Ladner RD, Prise KM, O'Sullivan JM, Harrison T, Murray L, Johnston PG, Waugh DJ. Delivering a researchenabled multistakeholder partnership for enhanced patient care at a population level: The Northern Ireland Comprehensive Cancer Program. Cancer. 2016; 122: 664-73

II. Lewis C, McQuaid S, Hamilton PW, Salto-Tellez M, McArt D, James JA. Building a 'Repository of Science': The importance of integrating biobanks within molecular pathology programmes. Eur J Cancer. 2016; 67:191-199

I2 Flynn C, James J, Maxwell P, McQuaid S, Ervine A, Catherwood M, Loughrey MB, McGibben D, Somerville J, McManus DT, Gray M, Herron B, Salto-Tellez M. Integrating molecular diagnostics into histopathology training: the Belfast model. J Clin Pathol. 20I4; 67:632-6.

13. Autier P, Boniol M, La Vecchia C, Vatten L, Gavin A, Héry C, Heanue M. Disparities in breast cancer mortality trends between 30 European countries: retrospective trend analysis of WHO mortality database. BMJ. 2010; 34I:c3620

14. https://www.qub.ac.uk/research-centres/nicr / 
15. Allemani C, Matsuda T, Di Carlo V, Harewood R, Matz M, Nikšić M, Bonaventure A, Valkov M, Johnson CJ, Estève J, Ogunbiyi OJ, Azevedo E Silva G, Chen WQ, Eser S, Engholm G, Stiller CA, Monnereau A, Woods RR, Visser O, Lim GH, Aitken J, Weir HK, Coleman MP; CONCORD Working Group. Global surveillance of trends in cancer survival 2000-14 (CONCORD-3): analysis of individual records for 37513025 patients diagnosed with one of 18 cancers from 322 population-based registries in 71 countries. Lancet. 2018 Mar I7;39।(10125):1023-1075

16.https://www.hse.ie/eng/services/list/5/cancer/pubs/reports/national\%20cancer\%20strategy \%201996.pdf

17. https://www.hse.ie/eng/services/list/5/cancer/pubs/reports/a-strategy-for-cancer-controlin-ireland.pdf

18. https://www.gov.ie/en/publication/a89819-national-cancer-strategy-2017-

2026/?referrer=/blog/publications/strategy-for-cancer-control-in-ireland/

19. https://nican.hscni.net//files/cancer_control_programme.pdf

20. https://www.sfi.ie/funding/funding-calls/us-ireland-rd-partnership/

2I. http://www.precisiononcology.ie/ 


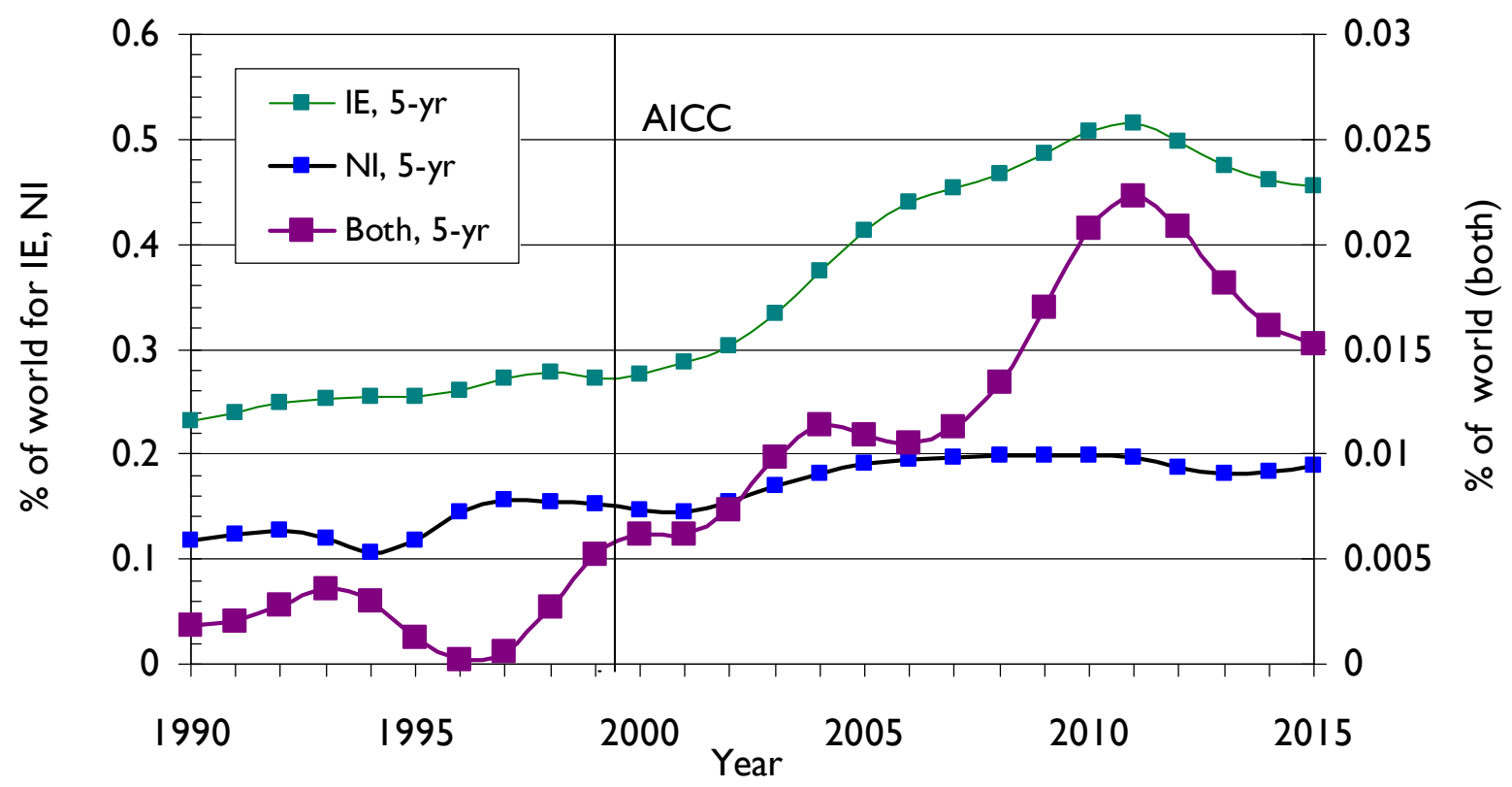

Figure I. Outputs of cancer research papers from Ireland (IE), from Northern Ireland (NI), and from both regions, all as percentages of the world total, 1988 to 2017 expressed as fiveyear running means. AICC = All Ireland Cancer Consortium 


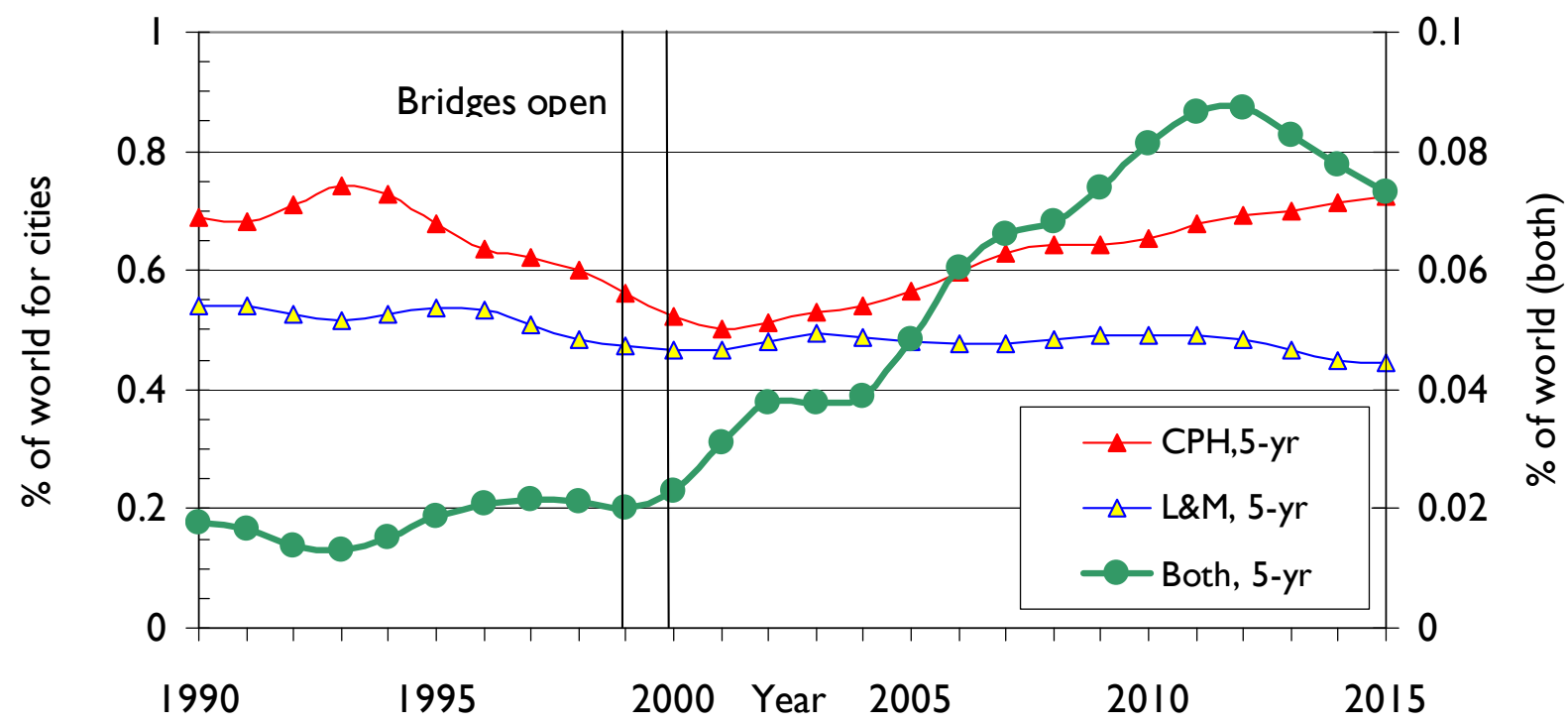

Figure 2. Outputs of cancer research papers from Copenhagen $(\mathrm{CPH})$, from Lund plus Malmö (L\&M), and from both city regions, all as percentages of the world total, 1988 to 2017 expressed as five-year running means. Bridges open indicates the timing of the opening of the Great Belt and Øresund bridges 


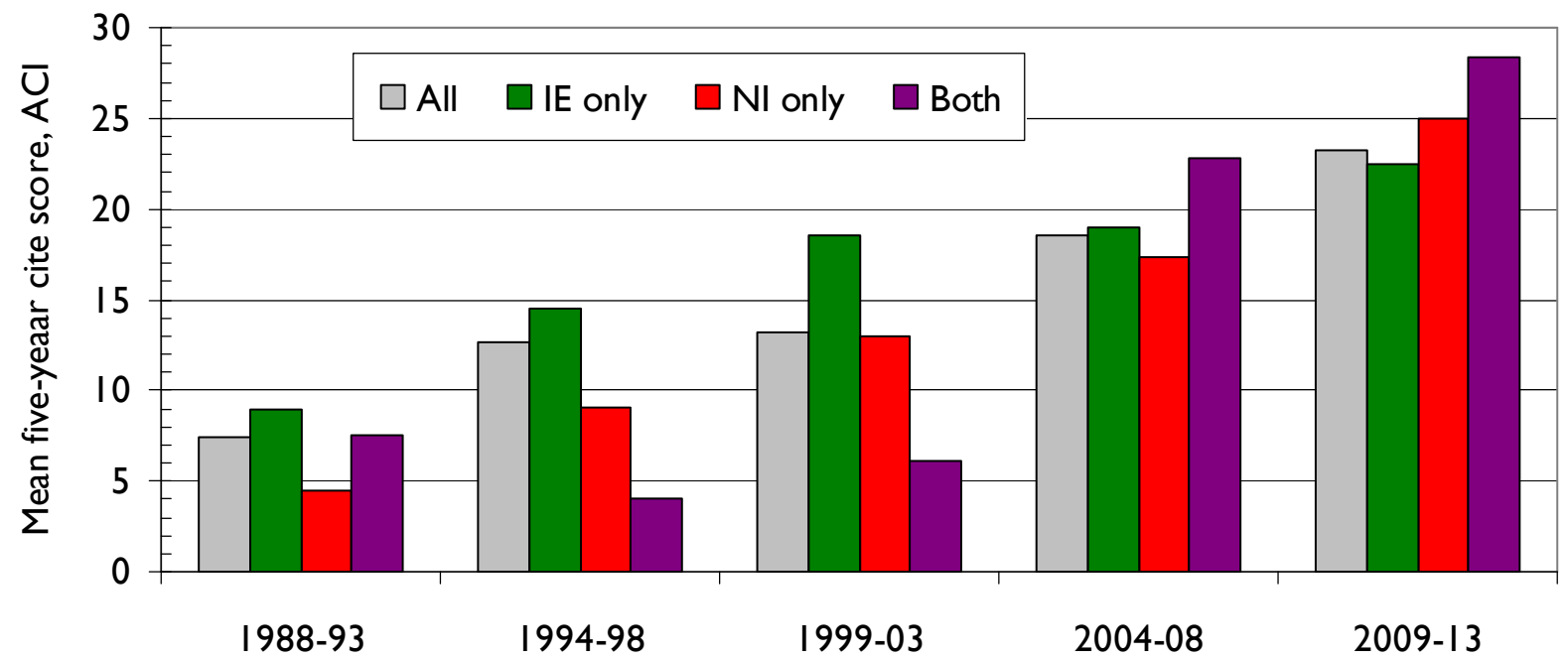

Figure 3. Five-year citation performance $(\mathrm{ACl})$ of Ireland $(\mathrm{IE})$ and Northern Ireland $(\mathrm{NI})$ cancer papers from 1988 to 2013 (arithmetic means, integer counts). 


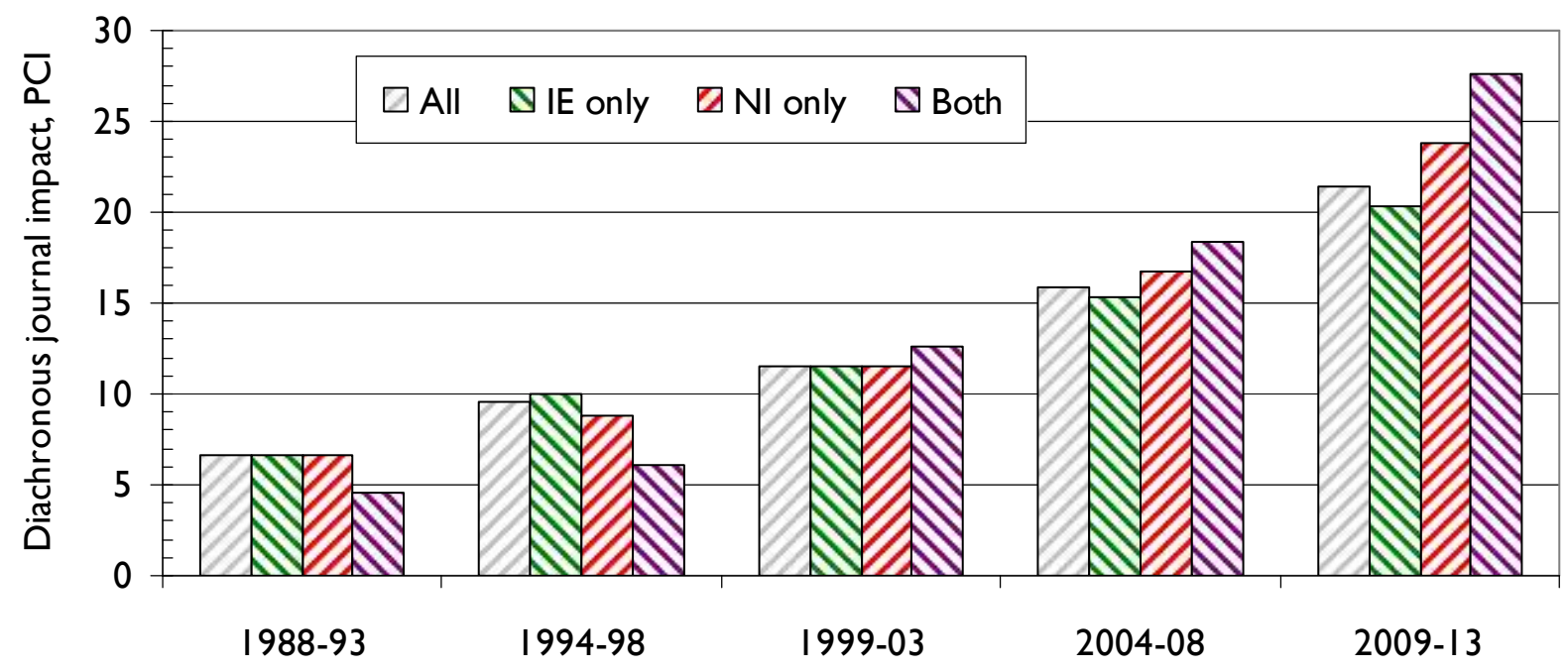

Figure 4. Five-year diachronous journal impact (PCl) of Ireland (IE) and Northern Ireland (NI) cancer papers from 1988 to 2013 (arithmetic means, integer counts). 


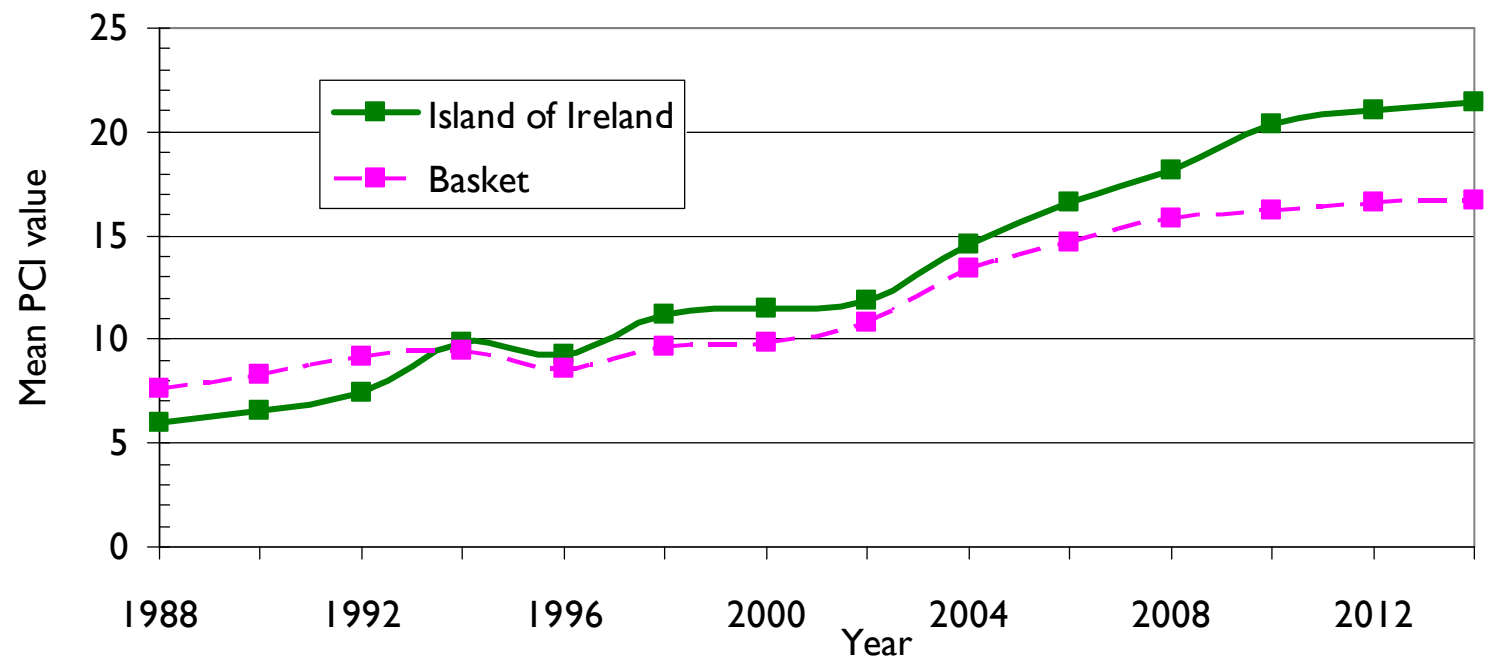

Figure 5. Mean potential citation impact (PCl) factor for a "basket" of II 28 journals in which island of Ireland cancer researchers published their papers in 1988-20I4, and the mean $\mathrm{PCl}$ for the island of Ireland papers themselves. [The "basket" consists of one paper in each of the journals in which an island of Ireland paper was published in the year stated.] 


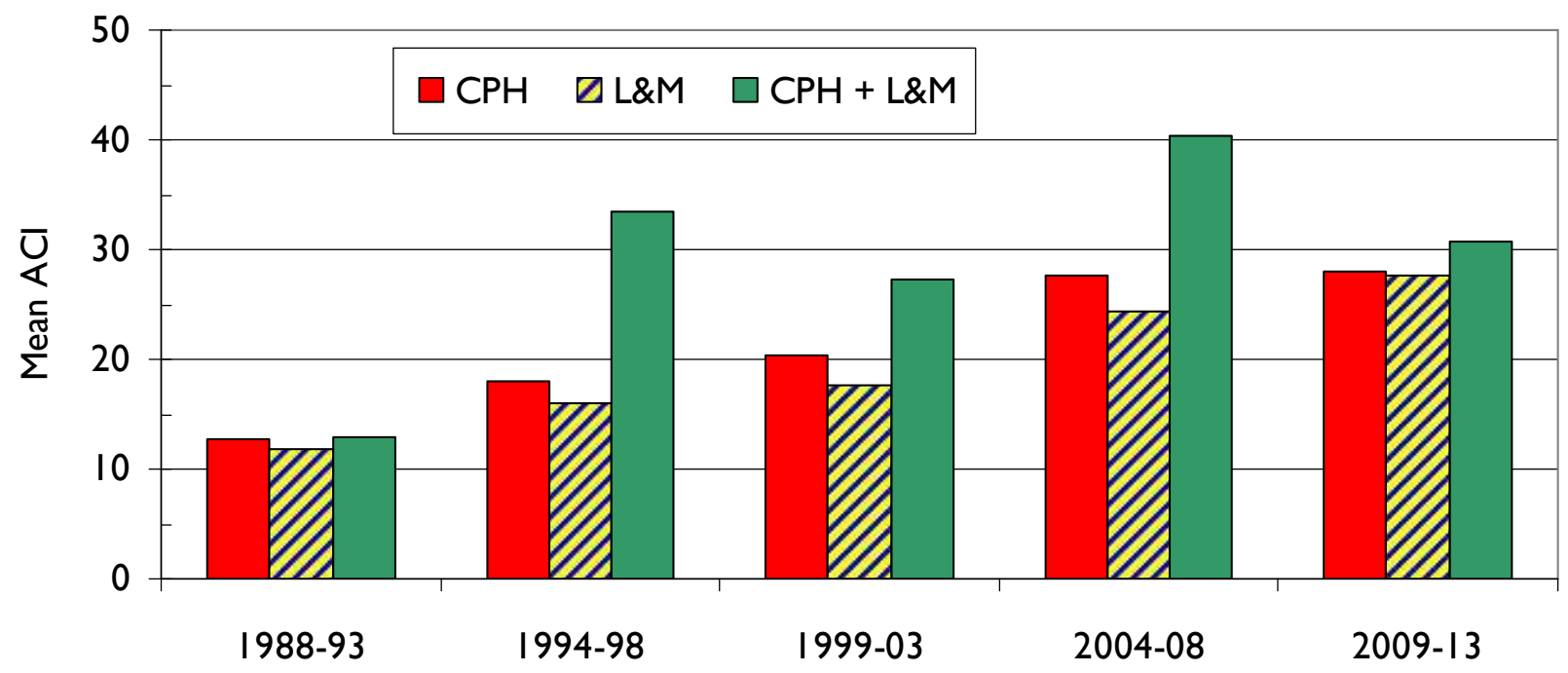

Figure 6. Five-year citation performance of Copenhagen (CPH) and Lund + Malmö (L\&M) cancer papers from 1988 to 2013 (arithmetic means, integer counts). 


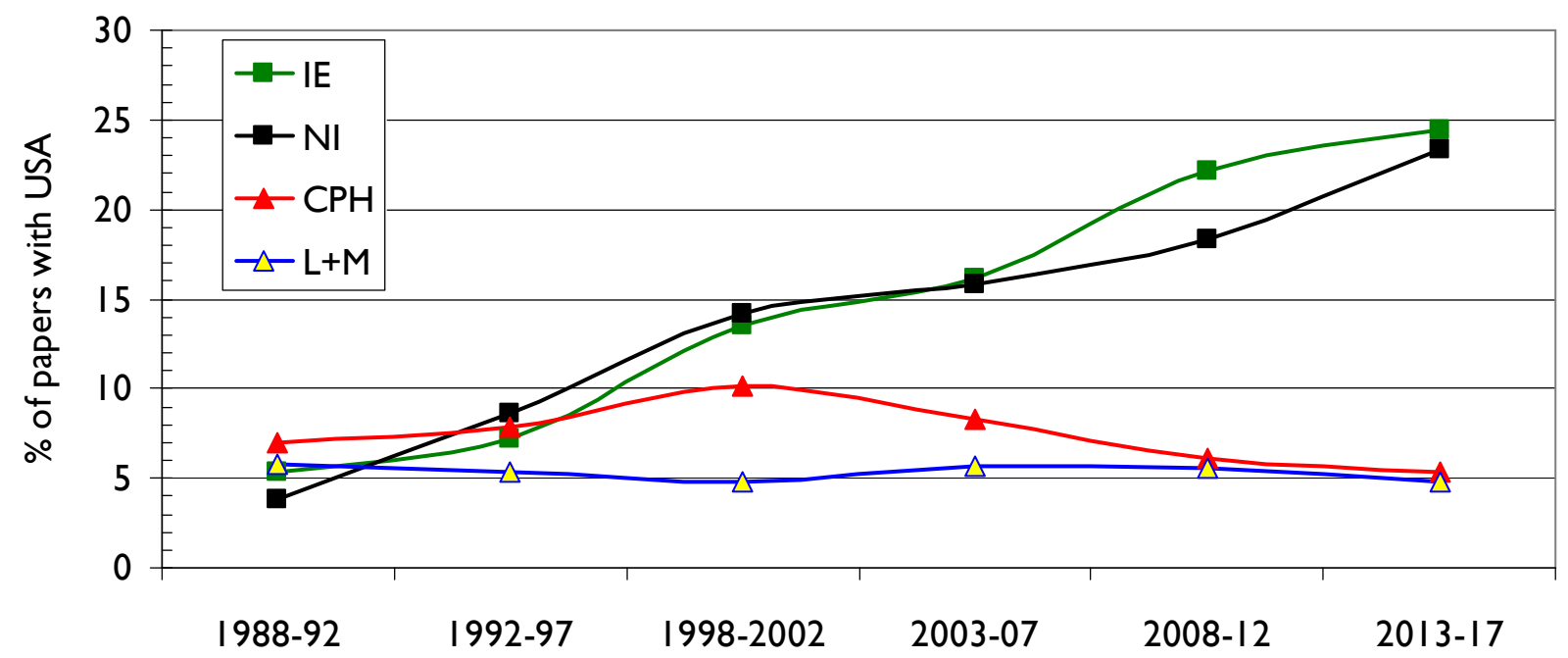

Figure 7. Collaboration between the four regions (Ireland (IE), Northern Ireland (NI), Copenhagen $(\mathrm{CPH})$ and Lund \& Malmö $(\mathrm{L}+\mathrm{M})$ ) and the USA for cancer research between 1988 and 2017 , integer counts. 


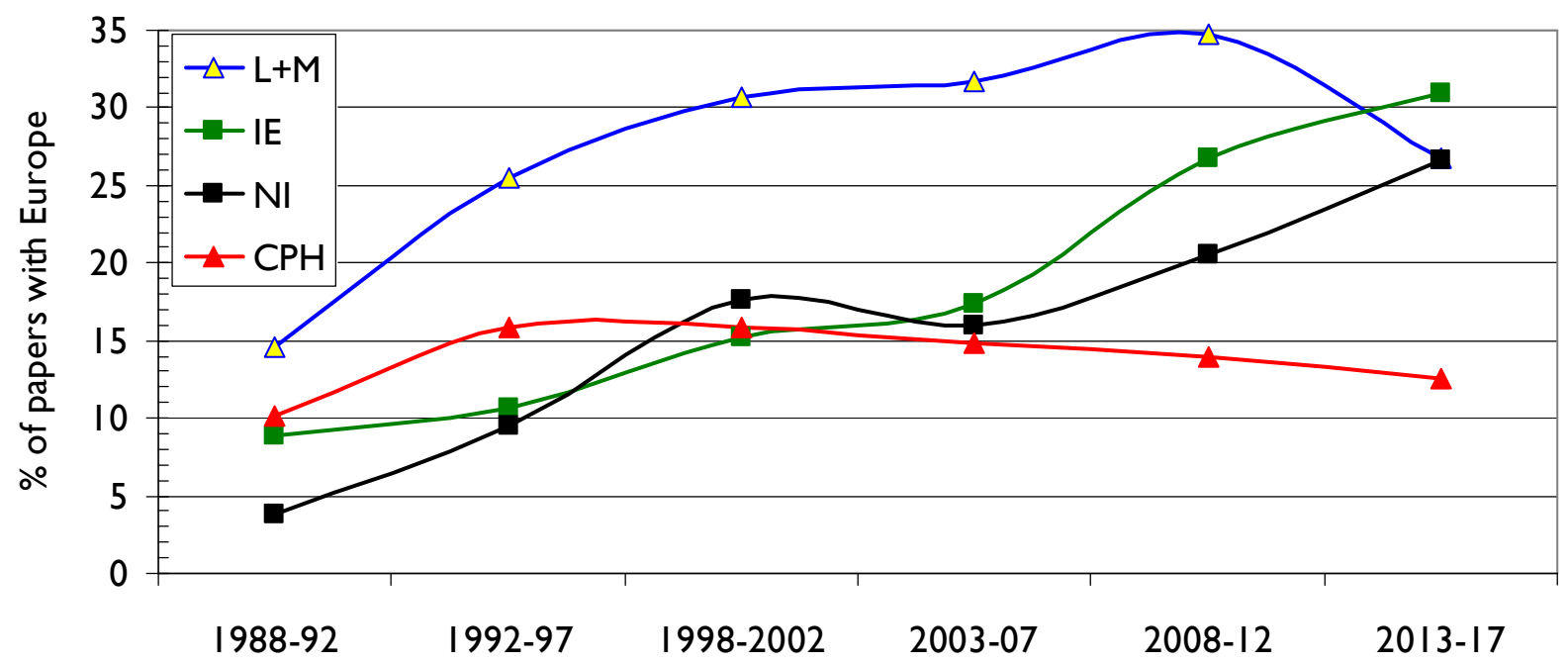

Figure 8. Collaboration between the four regions (Ireland (IE), Northern Ireland (NI), Copenhagen (CPH) and Lund \& Malmö $(L+M))$ and the rest of Europe between 1988 and 2017 for cancer research, integer counts. 


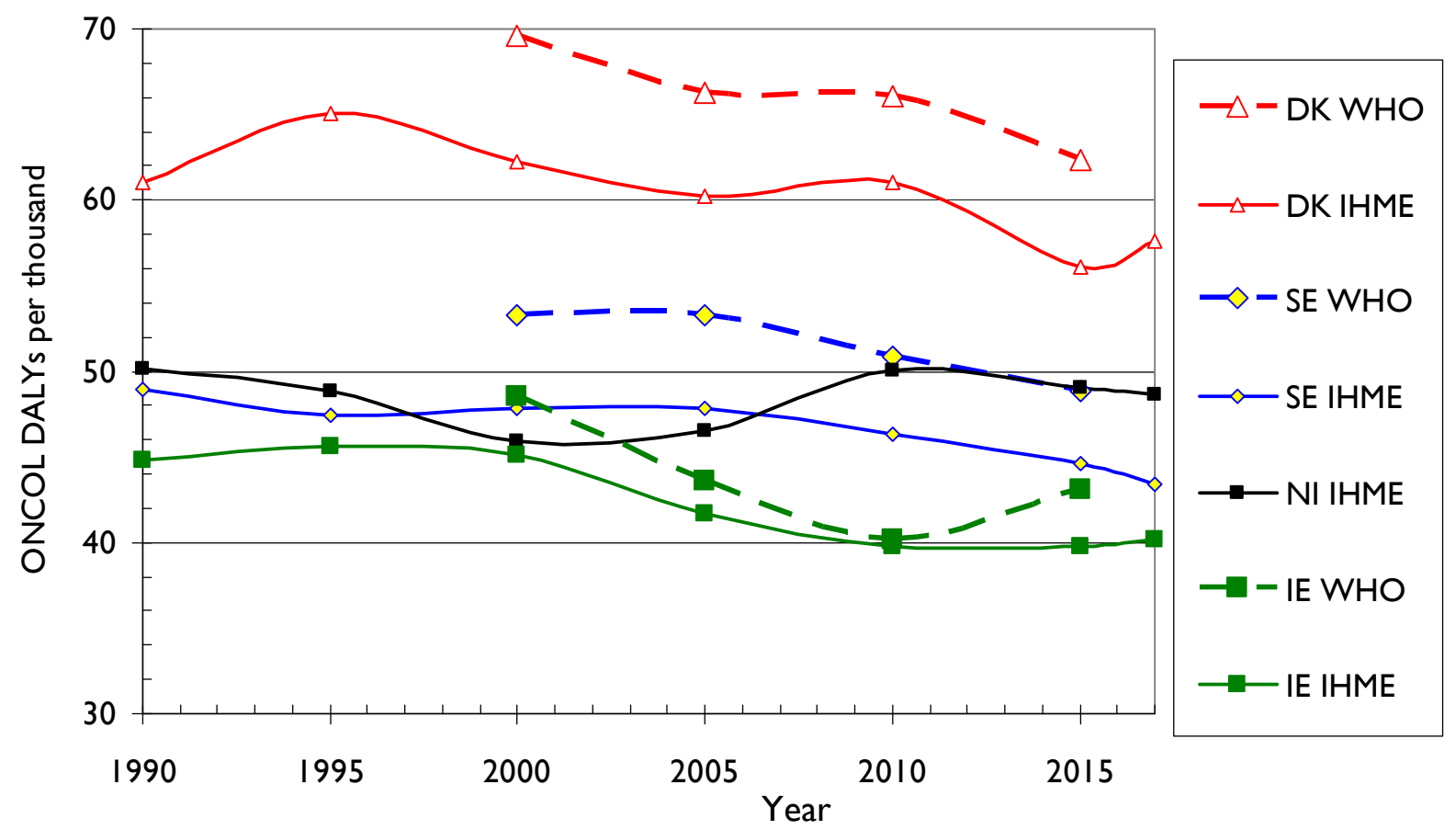

Figure 9. Burden from cancer (DALYs per thousand people) in Ireland (IE), Northern Ireland (NI), Denmark (DK) and Sweden (SE) over the period 1990 to 2017. Data from the World Health Organization (WHO) and the Institute for Health Metrics and Evaluation (IHME) at the Un 